Research Article

\title{
Boosting Up Operational Performance of Manufacturing Organizations through Interpretive Structural Modelling of Enabling Practices
}

\author{
Asif Arshad Ali, ${ }^{1}$ Asif Mahmood (iD, ${ }^{2}$ Ayyaz Ahmad, ${ }^{1}$ and Amir Ikram ${ }^{3}$ \\ ${ }^{1}$ Institute of Quality \& Technology Management, University of the Punjab, Lahore, Pakistan \\ ${ }^{2}$ Department of Business Studies, Namal Institute, Mianwali, Pakistan \\ ${ }^{3}$ National College of Business Administration \& Economics, Lahore, Pakistan
}

Correspondence should be addressed to Asif Mahmood; mahmood.engineer@gmail.com

Received 10 January 2020; Accepted 1 May 2020; Published 25 May 2020

Academic Editor: Luigi Rodino

Copyright $\odot 2020$ Asif Arshad Ali et al. This is an open access article distributed under the Creative Commons Attribution License, which permits unrestricted use, distribution, and reproduction in any medium, provided the original work is properly cited.

For achieving world-class performance and competitiveness in today's global highly complex environment and competition, there is an immense pressure on manufacturing organizations having limited resources to pursue operational excellence in terms of productivity and quality, reduce cost, and provide high-quality products in shorter lead times. Identification of representative practices affecting operational performance $(\mathrm{OP})$ and understanding of mutual dependence among those practices will improve the performance of manufacturing organizations with available resources. A sample of 10 experts of academicians and senior company managers from different functional areas of large-scale textile, sugar, and cement industries were surveyed to identify critical practices influencing OP and then to develop the relationships among them. It also identifies those practices that support other practices (driving practices) and also those that are most influenced by other practices (dependent practices). Firstly, through in-depth review of relevant literature, 10 most influencing practices were identified. Then expert elicitation was employed, and a hierarchical structure was established by using interpretive structural modelling (ISM) technique. After determining driving and dependence power of practices, classification or clusters of these practices were made through an additionally carried out MICMAC (cross-impact matrix multiplication applied to classification) analysis. The results contribute that lean management, organizational culture, ISO 9001 (quality management system), and human resource management practices indicate strong driving power and are at the bottom of ISM model. This is a novel and useful application of ISM to identify inherent interactions among these practices and construct a structural graph. With the help of this strategic understanding, researchers and practitioners will be able to identify the focal areas and to pay more attention to driver practices to effectively incorporate them at their strategic and operational levels and the effectiveness in addressing these driver practices will influence the OP to a large extent.

\section{Introduction}

In developing countries, economic development, Gross Domestic Product (GDP) growth, poverty reduction, and jobs creation depend largely on the success of manufacturing organizations because of the labour intensive nature [1]. Since manufacturing sector plays a role of growth engine in any nation's economy and has a favourable relationship with improved quality of life, improvement in operations efficiency and effectiveness should be the main objective of manufacturing organizations [2]. Organizations often have more control on OP because this kind of performance is less affected by external factors. Reduction in management cost, lead time, and order time, effective usage of raw material, and enhancing production activities' effectiveness refer to OP improvement [3]. In manufacturing facilities, cost, quality, delivery, flexibility, and rate of new product introduction are different measures to improve OP $[4,5]$. According to Modgil and Sharma [6] and Marodin, Frank [7], cost, quality, defects minimization, delivery, innovation, least possible work in progress, and capacity utilization are the core and most often mentioned dimensions of OP in 
manufacturing organizations. However, due to limited resources, change in customer expectations, growing demand for innovativeness, and volatility in market and leadership style, OP of manufacturing organizations is not up to the satisfactory level [1]. Also, there is lack of making long-term strategies because manufacturing organizations are entirely engaged on unravelling their short-term operational problems [8].

Numerous researchers have extensively studied and identified the number of practices that can affect and drive the performance of manufacturing organizations. However, these practices and their association with the OP have been emphasized largely in isolation overlooking the investigation of comparative effects. Moreover, because they do not operate independently, their interrelations are very important to study. The presence of direct and indirect relation among those practices makes the structure of system very complex and it is very difficult to deal with such system of unclear and undefined structure. The existing studies [e.g., 2, 22, 54,] have not examined or analysed the interactions between these practices. Therefore, the current study aims to fill this gap by developing a comprehensive framework to deal with such types of problems in an effort to impose order and direction on the complexity of relationships among practices influencing $\mathrm{OP}$ of manufacturing organizations. For relationship identification among different elements, interpretive structural modelling (ISM) is a suitable methodology and this approach is easily communicable and easy to use [9]. In ISM, data are collected through different interactive techniques such as brainstorming, focus group discussion, Delphi method, nominal group techniques, and so forth, and collective knowledge of groups of people is configured or organized [10]. The ISM approach is preferable because it is interpretive and iterative in nature. Moreover, hierarchical structure and partition levels are defined in ISM, and then, on the base of driving and dependence power, these practices are categorized through MICMAC analysis. Any hidden relationships of somewhat low weightage can be considered by applying MICMAC because it increases the sensitivity of relationships among elements. This study demonstrates the driving power and dependence power of individual practices and the model proposed in the current study is a useful tool for manufacturing organizations to focus on those practices that are most important (drivers) and to address and consistently track them for their strategic orientation.

Based on the research gap, this study aims to address the following research questions: (1) What are the key practices that affect operational performance of manufacturing organizations? (2) How to identify interrelationships among the identified key practices using ISM to support the evaluation of performance? (3) How to classify these practices into four different clusters through MICMAC analysis?

The remainder of the paper is organized as follows: identification of different practices based on literature is elaborated in Section 2. A hybrid methodology consisting of ISM and MICMAC is introduced in Section 3. This methodology is applied in Section 4 to demonstrate the interrelationships among influencing practices and to classify those practices, followed by discussion (Section 5). Finally, Section 6 draws the overall conclusions and practical implications based on results from Section 4.

\section{Literature Review}

Over the globe, manufacturing companies struggle to achieve excellence in their operations in terms of improved quality, productivity, and reduced cost. Enhancing OP includes improving different production activities for the purpose of creating high-quality products, which leads to revenue generation and profit maximization [3]. In this regard, several practices are the main contributors in enhancing performance. Based on extensive literature review, different practices have been identified, which make an organization operationally efficient. For further analysis, the ten main practices or constructs that drive OP and have been cited in multiple researches have been selected. A summary of 10 practices along with related references have been presented in Table 1.

2.1. TQM. In the current era of fierce competition, there is much emphasis in literature on the relationship between TQM practices and OP. TQM practices play an important role for manufacturing organizations to stay at competitive edge. Manufacturing performance improves if the level of implementation of TQM practices is higher [11]. To a greater extent, TQM practices are used in outcome-oriented and innovative organizations and process management, supplier quality management, and quality data and reporting are more significant TQM practices for enhancing quality and inventory management [12]. By implementing quality management practices, there is improvement in operational outcomes of firms even having limited resources [13]. Also, the operating performance mediates the relationship between TQM practices and market and financial performance [14].

2.2. Process Innovation. In any industry, an essential element or most important determinant for gaining competitive edge is innovation, also called idea creation process. Ideation and organizing structures, participatory leadership culture, and know-how development are different aspects of innovation capability in an organization and are found as influential to operational and financial performance [18]. According to Hung, Lien [17], there are 3 types of innovations: product innovation, process innovation, and overall organizational innovation. Different dimensions of process innovation are quality production and processes, flexibility in processes, and cost reduction ability. Product innovation and process innovation are included in technological innovation, while marketing and organizational innovation are part of nontechnological innovation. The technological innovation is significantly related to performance [15]. For improving OP or internal processes in terms of efficiency and productivity in manufacturing organizations, focus on process innovation is recommended, while product innovation has impact on other aspects of performance such as financial 
TABLE 1: Literature support to different practices impacting operational performance.

\begin{tabular}{lcc}
\hline Practice code $(P)$ & Practice or construct & Supported by \\
\hline$P 1$ & Total quality management (TQM) & {$[11-14]$} \\
$P 2$ & Process innovation (INV) & {$[15-18]$} \\
$P 3$ & Lean management (LM) & {$[19-22]$} \\
$P 4$ & Organizational culture (OC) & {$[23-25]$} \\
$P 5$ & Six sigma $(6 \sigma)$ & {$[26-29]$} \\
$P 6$ & Human resource management (HRM) & {$[4,30,31]$} \\
$P 7$ & ISO 9001 (QMS) & {$[32-34]$} \\
$P 8$ & Research \& development (R\&D) & {$[35-38]$} \\
$P 9$ & Enterprise resource planning system (ERP) & {$[39-42]$} \\
$P 10$ & Supply chain management (SCM) & {$[3,43]$} \\
\hline
\end{tabular}

performance and market share. Furthermore, it is necessary to have process innovation for achieving sustainable performance, which is very difficult to imitate [16].

\subsection{Lean Management. Lean management (LM) is helpful in} reducing cost and lead times in work-in-process inventories and improving customer satisfaction. Also implementation of lean practices leads to high levels of quality because these practices strive to reduce variability and non-value-added activities and target the prevention from defects [21]. At operational and strategic level, application of lean is modified according to new environment's requirements [22]. There are $13 \mathrm{LM}$ practices that have been categorized into three main constructs through factor analysis, namely, just in time (JIT), waste minimization, and flow management. Six practices or items included in JIT are inventory reduction, preventive measures, minimizing cycle time, new process techniques, use of quick change-over techniques, and arrangement/operation time minimization. Waste elimination, error proofing procedure, use of pull-based production system, and bottlenecks removal are the four practices included in waste minimization, whereas three items included in flow management are minimizing lot size, single supplier focus, and continuous piece flow [19]. Because all LM practices are interdependent, they must be implemented collectively but not as individual practice for obtaining sustainable outcomes. These practices have a positive link with operational effectiveness and business performance, while the former also acts as a mediator between LM practices and business performance [20].

2.4. Organizational Culture. In an organization, sharing of values, beliefs, and assumptions by members is termed as organizational culture that is considered an organizational resource or asset and it distinguishes one organization from another. Since when employees feel good they perform better, a culture involving enjoyment, flexible working hours, and creativity is desirable. On the basis of two dimensions, which are between control and flexibility orientations and between external and internal orientations, there are four types of culture: rational, developmental, group, and hierarchical [23, 24], among which rational and group cultures have positive and direct impact on $\mathrm{OP}$, while developmental culture has indirect relationship with OP.
Meanwhile, hierarchical culture has both direct and indirect influence on organizational performance at operational level [23]. In an organization, it is more valuable to have a combination of different sorts of organizational cultures rather than a certain kind of culture [25].

2.5. Six Sigma. Six sigma (a value creating) concept was created in 1985 by Motorola Inc., mainly owing to the threat of Japanese competition. Major development in management practices is the emergence of six sigma and its successful implementation improves various aspects of performance and will guarantee attaining competitive advantage [28]. Six sigma is different from other process improvement programs (e.g., TQM, lean, ISO 9000) in that it is helpful in problem solving and exploration across the organization, acts organically when a firm faces new challenges, and operates mechanically for focusing on efficiency. Six sigma seeks to reduce operations' cost and cycle times, improve productivity, meet customer expectations, and achieve higher utilization of assets [29]. Application of six sigma removes defects' root cause instead of searching for the defects, while the operational efficiency of manufacturing organizations improves near to perfection after six sigma application [26, 27].

2.6. Human Resource Management. Human resource management (HRM) is equally important for both manufacturing and service organizations. There are seven HRM practices, employment security, careful hiring of new staff, decentralization, high compensation, on-job training, status reduction, and sharing of information, throughout the firm [4], which play an important role in the creation of better human capital, and retention of such capital or main assets in an organization leads to sustainable competitive advantage [31]. In the past, mostly research was conducted to understand the role of HRM practices on efficiency, employee turnover, and financial performance. However, there is dearth of literature that discusses the impact of HRM practices on OP measures [4]. In manufacturing organizations, different HRM practices, for example, recruitment and selection, communication and involvement, evaluation of performance, and employee relationship, have a significant relationship with OP [30]. 
2.7. ISO 9001 (QMS). ISO 9000 family of standards was developed by International Organization for Standardization (ISO) and contains ISO's best known standards, and ISO 9001 is one from them. In these standards, there are tools and guidance for those organizations that want their offering to constantly satisfy customer's requirements. ISO 9001 standard has been revised several times in order to make it more responsive and fulfil the changing requirements of companies or market. Sometimes it becomes necessary to have ISO 9001 certificate in view of customers' demand and satisfaction [32]. Feng, Terziovski [33] also confirmed that external reasons like competitive pressure and customers' expectation are the motivation for undertaking ISO 9001 certification but now this motivation is shifting from external to internal reasons for quality improvement and preventing nonconformities in products and services. Well-planned implementation of quality management system (QMS) or ISO 9001 in its true sense coupled with periodic audits, employee's training, commitment, and corrective action at all levels of the organization leads to substantial improvements in the internal operations of a company $[33,34]$.

2.8. Research and Development. Acquiring new knowledge for creating novel products, services, system, or technology is known as research and development (R\&D) process. There is investment in R\&D up to some level in every kind of organizations. In manufacturing and service firms, there is positive contribution of R\&D investment to firm's performance [35]. Understanding empirical relationship between $R \& D$ and competitiveness is much important for managers, board of directors, and policy makers for formulating strategic economic policies [36]. Klette [37] also confirms that $R \& D$ is an explanatory variable of performance at plant level. For differentiation between successful and unsuccessful organizations, $\mathrm{R} \& \mathrm{D}$ capability is considered a prime competence. For the survival of company's operation, R\&D capabilities are the crucial elements. Among various $R \& D$ capabilities, intellectual property right (IPR) is the core element which is the protection of one's own effort in the creation of new inventions or products. For enhancing $R \& D$ toward OP, IPR acts as a stimulus [38].

2.9. ERP System. In this era, importance of enterprise resource planning (ERP) system cannot be denied in any organization due to its competitiveness over nonadopters of ERP system [39]. As ERP system automates the business processes, it has positive influence on cost reduction, cycle time reduction, productivity and quality improvement, and customer services upgradation, which are different aspects of OP [40]. ERP is not only a cost cutting tool but also supports a business strategy that pursues innovation and growth [42]. ERP system enhances the efficiency and effectiveness of an organization in the use of different resources such as human resources, finances and materials, and so forth and integrates different business processes [39]. Therefore, implementing ERP system in an organization is a fruitful investment for improving OP. Based on literature review, there are 14 modules of ERP system, and influence of each module of ERP system is different on OP dimensions [41].

2.10. Supply Chain Management. In this competitive world, real competition is among organizations' supply chains but not among the organizations, and, for improving OP, it is essential to employ SCM practices. Strategic supplier partnership, customer relationship, information sharing by each business partner, IT implementation, training and quality, and reliability of internal operations are SCM dimensions that have positive and significant relationship with organizational performance [43]. Truong, Sameiro [3] also confirmed that reliable predictors of competitive priorities (cost, quality, delivery, and flexibility) are SCM practices and foundation of OP improvement in any organization is the implementation of SCM practices and major variance of performance is explained by these practices.

All practices stated above play an important part in enhancing performance of manufacturing organizations but it is very difficult or likely impossible to pay full attention to all these practices at once. So, it is imperative for enterprises with limited resources to recognize and exploit those practices that are crucial and act as drivers for others. Also, it is easy to focus on limited number of factors than to pursue all of them.

\section{Methodology}

The study has employed a hybrid approach as shown in Figure 1. Initially, identification of critical practices affecting operational performance was carried out through literature survey. Then, opinion of 10 experts, academicians and senior company managers (presidents, CEOs and directors, or managers of different functional areas), of large-scale textile, sugar, and cement industries was collected through a survey questionnaire in order to determine the contextual relationships among these practices. The reason behind their selection was that they were well conversant with all those practices that have an influence on OP. In the current study, 18 experts were contacted, and 10 experts (four from academia and six from industry) finally agreed to participate, and their opinions are considered effective for analysis because they all belong to authoritative organizations. By aggregating the expert opinion, initial reachability matrix was obtained through interpretive structural modelling. That was followed by power analysis to calculate the final reachability matrix and hierarchical structure. Finally, for the classification of these practices, MICMAC technique is used. It is important to state here that this research does not require consent from ethical committee because data were analysed, and the results are presented anonymously. The results are based upon the unidentifiable opinion of the experts.

3.1. Interpretive Structural Modelling. Warfield [44] was the first to propose an approach called interpretive structural modelling (ISM), a powerful qualitative tool, and a suitable modelling technique. Using knowledge and practical 


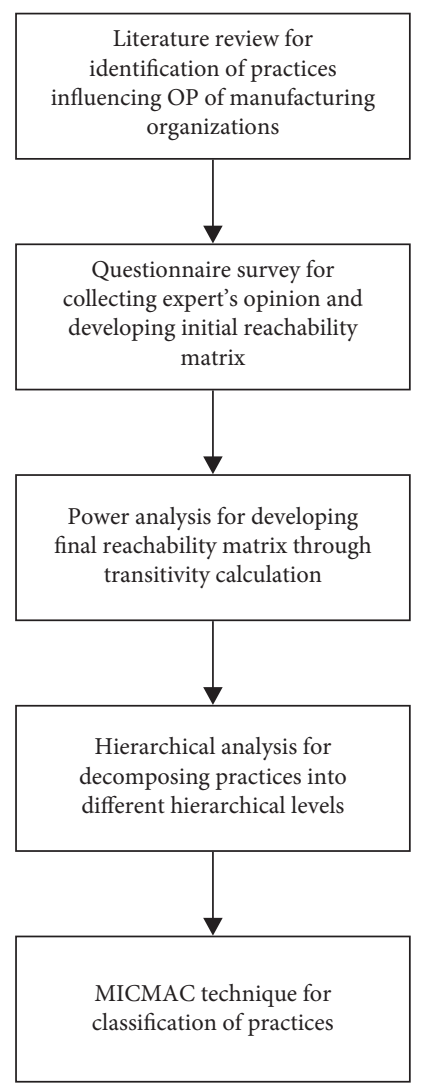

FIgURE 1: Research process.

experience of experts to build a structural model after decomposing a complicated system is the main logic behind this approach. ISM helps an individual to break down the complexity of different issues into manageable masses of information by focusing on interrelationship among elements. Unclear and poorly articulated data are transformed into a well-defined hierarchal model through this approach. Both individuals and groups can apply ISM to structure a comprehensive and systematic model from a set of various different and directly linked elements [45]. A number of researchers have applied ISM technique it in their studies for analysing contextual links among elements. For implementing integrated educational quality management system (IEQMS), various critical success factors were analysed by Pandi, Sethupathi [46] through this approach, and, for fruitfully implementing information technology in higher education institutions, different potential barriers were identified and prioritized through ISM technique by Garg, Shukla [47]. Also, for successfully implementing TQM practices in manufacturing sector, Muruganantham, Vinodh [11] analysed different barriers and presented a framework showing mutual relationship among those barriers using ISM.

ISM methodology includes the following steps $[48,49]$ :

(1) Identification of practices influencing OP through survey.

(2) Establishment of contextual relationships among elements identified in previous step for showing whether one element leads to another or not.
(3) Development of structural self-interaction matrix (SSIM) for showing a pairwise relationship between elements.

(4) Formation of reachability matrix (RM) from SSIM and for observing transitivity, checks the matrix, which is the basic assumption in ISM stating that if element $X$ is related to $Y$ and element $Y$ is related to $Z$ then it means $X$ is necessarily related to $Z$. SSIM format is converted in the format of RM through converting the information in each entry of SSIM into $1 \mathrm{~s}$ and $0 \mathrm{~s}$ of RM. It can be said that subjective data is converted into quantitative values in RM.

(5) Establishment of different levels by segregating or partitioning the reachability matrix.

(6) Based on relationships given in RM, draw a directed graph and remove the transitive links.

(7) Construction of ISM model.

(8) For checking any inconsistency, appraise or analyse the ISM model and take required and crucial actions accordingly.

3.2. MICMAC. Scope of each practice is critically investigated through an indirect classification technique called MICMAC (cross-impact matrix multiplication applied to classification) analysis developed by Duperrin and Godet [50] and this technique is centred on each practice's driving and dependence power. In MICMAC analysis, different practices impacting OP have been classified into four clusters or four quadrants (clusters), namely, autonomous, dependent, linkage, and independent.

\section{ISM Based Analysis and Discussion}

4.1. Structural Self-Interaction Matrix (SSIM) Development. To categorize the relationship between any two practices, a value of $V, A, X$, or $O$ was used in structured questionnaire according to the rules given below:

(1) $V=$ practice $i$ affects practice $j$

(2) $A=$ practice $j$ affects practice $i$

(3) $X$ =interrelationship between $(i, j)$ practices will be helpful to achieve each other

(4) $O=$ there is not a relationship between $(i, j)$ practices

Experts' opinion based on various management techniques such as brainstorming, nominal group technique, and so forth was used to develop contextual relationships between each pair of practices. Respondents were asked to fill the questionnaire by answering 45 questions in which column statement is compared to the row statement. There was a question to the experts about the direct link between practices $i$ and $j$ and sharing of the same opinion from experts confirmed the relationship. Based upon these relationships, SSIM has been developed as shown in Table 2.

4.2. Initial Reachability Matrix (IRM) Formation. From the SSIM, there is development of IRM (shown in Table 3) by 
TABLE 2: Structural self-interaction matrix.

\begin{tabular}{|c|c|c|c|c|c|c|c|c|c|c|}
\hline Practices & $P 1$ & $P 2$ & P3 & $P 4$ & $P 5$ & $P 6$ & $P 7$ & $P 8$ & $P 9$ & $P 10$ \\
\hline$P 1$. Total quality management (TQM) & & $V$ & $A$ & $A$ & $X$ & $A$ & $A$ & V & $X$ & $X$ \\
\hline$P 2$. Process innovation (INV) & & & $A$ & $A$ & $A$ & $O$ & $A$ & $X$ & $A$ & $A$ \\
\hline P3. Lean management (LM) & & & & $X$ & $V$ & $X$ & $X$ & $V$ & $V$ & $V$ \\
\hline P4. Organizational culture (OC) & & & & & $V$ & $X$ & $\mathrm{X}$ & $O$ & $V$ & $V$ \\
\hline P5. Six sigma $(6 \sigma)$ & & & & & & $A$ & $A$ & V & $X$ & $X$ \\
\hline P6. Human resource management (HRM) & & & & & & & $X$ & $V$ & $V$ & $V$ \\
\hline P7. ISO 9001 (QMS) & & & & & & & & $O$ & $V$ & $V$ \\
\hline P8. Research \& development (R\&D) & & & & & & & & & $A$ & $A$ \\
\hline$P 9$. Enterprise resource planning system (ERP) & & & & & & & & & & $X$ \\
\hline
\end{tabular}

TABLE 3: Initial reachability matrix.

\begin{tabular}{lccccccccccc}
\hline Practices & $P 1$ & $P 2$ & $P 3$ & $P 4$ & $P 5$ & $P 6$ & $P 7$ & $P 8$ & $P 9$ & $P 10$ & Driving power \\
\hline$P 1$ & 1 & 1 & 0 & 0 & 1 & 0 & 0 & 1 & 1 & 1 & 6 \\
$P 2$ & 0 & 1 & 0 & 0 & 0 & 0 & 0 & 1 & 0 & 0 & 1 \\
$P 3$ & 1 & 1 & 1 & 1 & 1 & 1 & 1 & 1 & 1 & 1 \\
$P 4$ & 1 & 1 & 1 & 1 & 1 & 1 & 1 & 0 & 1 & 1 & 1 \\
$P 5$ & 1 & 1 & 0 & 0 & 1 & 0 & 0 & 1 & 1 & 1 & 9 \\
$P 6$ & 1 & 0 & 1 & 1 & 1 & 1 & 1 & 1 & 1 & 1 & 9 \\
$P 7$ & 1 & 1 & 1 & 1 & 1 & 1 & 1 & 0 & 1 & 1 & 9 \\
$P 8$ & 0 & 1 & 0 & 0 & 0 & 0 & 0 & 1 & 0 & 0 & 2 \\
$P 9$ & 1 & 1 & 0 & 0 & 1 & 0 & 0 & 1 & 1 & 1 & \\
$P 10$ & 1 & 1 & 0 & 0 & 1 & 0 & 0 & 1 & 1 & 1 & 6 \\
Dependence power & 8 & 9 & 4 & 4 & 8 & 4 & 4 & 8 & 8 & 8 & 6 \\
\hline
\end{tabular}

replacing the values of $V, A, X$, and $O$ into $1 \mathrm{~s}$ and $0 \mathrm{~s}$ according to equation (1).

$$
(i, j)= \begin{cases}V, & (i, j)=1,(j, i)=0 ; \\ A, & (i, j)=0,(j, i)=1 ; \\ X, & (i, j)=1,(j, i)=1 ; \\ O, & (i, j)=0,(j, i)=0 ;\end{cases}
$$

4.3. Final Reachability Matrix Formation. Here, there is development of final reachability matrix (FRM) through incorporation of transitivity represented by $1^{*}$. This is the elementary assumption of ISM, which states that if element $X$ is related to $Y$ and element $Y$ is related to $Z$ then it means $X$ is necessarily related to $Z$. According to the following Boolean rules, FRM was computed.

$$
R=(A+\mathrm{I})^{r}=(A+\mathrm{I})^{r-1} \neq(A+1)^{r-2} \neq \ldots \neq(A+1), r \leq 9 .
$$

In equation (2), $A$ represents initial reachability matrix, $I$ is unit matrix, $r$ represents less than or equal to number of practices, and final reachability matrix is shown by $R$. Driving and dependence power of each practice are also identified in this step. Sum of all ones in a row is the driving power of a particular practice, whereas dependence power of that practice is the sum of number of ones in a given column. Final reachability matrix has been shown in Table 4.

4.4. Hierarchical Analysis/Level Partitions. Reachability set $R$ (Pi) and antecedent set $A(\mathrm{Pi})$ for each practice are obtained from FRM. A particular practice and the other one which it may help achieve constitute the reachability set $R(\mathrm{Pi})$. On the other hand, a particular practice itself and the other variables that may influence it constitute the antecedent set $A(\mathrm{Pi})$. For all practices, intersection set $C(\mathrm{Pi})$ represents the intersection of corresponding $R(\mathrm{Pi})$ and $A(\mathrm{Pi})$. Top-level position is given to that factor, where $R(\mathrm{Pi})=C(\mathrm{Pi})$. It is because, above its own level, it is not helpful for achieving any other practice. Then this toplevel identified practice is removed from further analysis. The process is iterated for level identification of all practices. These levels are helpful for digraph building and for structuring the final ISM-based model. Hierarchical division or levels of all practices or constructs obtained through three iterations have been presented in Table 5 .

A digraph was drawn based on the above defined relationships (not shown here). Bottom to top approach is used in this model and each arrow in this structure represents "leads to." Then digraph is converted to interpretive structural model of practices by removing transitivity links and replacing the element nodes of digraph with statements to make the hierarchical structure clearer as shown in Figure 2. In this figure, information from Table 5 is used for obtaining ISM-based hierarchy structure between 10 
TABle 4: Final reachability matrix.

\begin{tabular}{lccccccccccc}
\hline Practices & $P 1$ & $P 2$ & $P 3$ & $P 4$ & $P 5$ & $P 6$ & $P 7$ & $P 8$ & $P 9$ & $P 10$ & Driving power \\
\hline$P 1$ & 1 & 1 & 0 & 0 & 1 & 0 & 0 & 1 & 1 & 1 \\
$P 2$ & 0 & 1 & 0 & 0 & 0 & 0 & 0 & 1 & 0 & 0 & 6 \\
$P 3$ & 1 & 1 & 1 & 1 & 1 & 1 & 1 & 1 & 1 & 1 \\
$P 4$ & 1 & 1 & 1 & 1 & 1 & 1 & 1 & $1^{*}$ & 1 & 1 & 10 \\
$P 5$ & 1 & 1 & 0 & 0 & 1 & 0 & 0 & 1 & 1 & 1 & 10 \\
$P 6$ & 1 & $1 *$ & 1 & 1 & 1 & 1 & 1 & 1 & 1 & 1 & 1 \\
$P 7$ & 1 & 1 & 1 & 1 & 1 & 1 & 1 & $1^{*}$ & 1 & 1 & 10 \\
$P 8$ & 0 & 1 & 0 & 0 & 0 & 0 & 0 & 1 & 0 & 0 & 1 \\
$P 9$ & 1 & 1 & 0 & 0 & 1 & 0 & 0 & 1 & 1 & 1 & \\
$P 10$ & 1 & 1 & 0 & 0 & 1 & 0 & 0 & 1 & 1 & 1 & 6 \\
Dependence power & 8 & 10 & 4 & 4 & 8 & 4 & 4 & 10 & 8 & 8 & 6 \\
\hline
\end{tabular}

TABLE 5: Hierarchical division of practices.

\begin{tabular}{lcccc}
\hline Practices & $R(\mathrm{Pi})$ & $A(\mathrm{Pi})$ & $C(\mathrm{Pi})$ & Level \\
\hline INV & 2,8 & $1,2,3,4,5,6,7,8,9,10$ & 2,8 & 1 \\
R\&D & 2,8 & $1,2,3,4,5,6,7,8,9,10$ & 2,8 & 1 \\
TQM & $1,5,9,10$ & $1,3,4,5,6,7,9,10$ & $1,5,9,10$ & 2 \\
$6 \sigma$ & $1,5,9,10$ & $1,3,4,5,6,7,9,10$ & $1,5,9,10$ & 2 \\
ERP & $1,5,9,10$ & $1,3,4,5,6,7,9,10$ & $1,5,9,10$ & 2 \\
SCM & $1,5,9,10$ & $1,3,4,5,6,7,9,10$ & $1,5,9,10$ & 2 \\
LM & $3,4,6,7$ & $3,4,6,7$ & $3,4,6,7$ & 3 \\
QMS & $3,4,6,7$ & $3,4,6,7$ & $3,4,6,7$ & 3 \\
HRM & $3,4,6,7$ & $3,4,6,7$ & $3,4,6,7$ & 3 \\
OC & $3,4,6,7$ & $3,4,6,7$ & $3,4,6,7$ & 3 \\
\hline
\end{tabular}

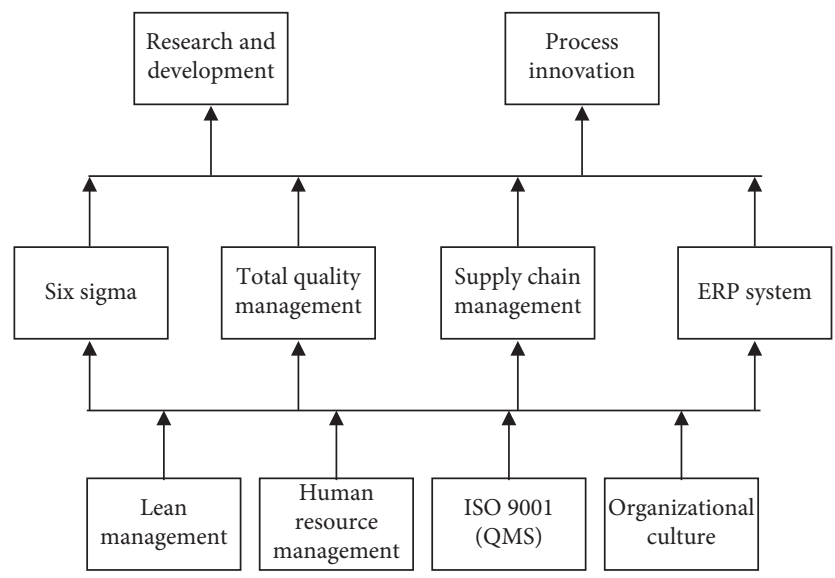

FIGURE 2: Hierarchical structure of practices influencing OP.

practices, and it is clear that practices at same level in aforementioned analysis have been placed in the same layer.

LM, QMS, OC, and HRM practices are four fundamental variables affecting performance of manufacturing organizations. They influence other practices directly or indirectly. Meanwhile, at top of the model, there are R\&D and process innovation constructs related to OP. Indirect variables influencing $\mathrm{OP}$ are the practices in the middle layer. They are $6 \sigma$, ERP system, TQM, and SCM. An overview of interpretive structural model shows that improvement in LM, QMS, OC, and HRM practices is the most fundamental for enhancing OP of manufacturing organizations.
4.5. Clustering of Practices (MICMAC Analysis). MICMAC analysis is an indirect classification technique used for critical investigation of each practice's scope. The key objective of MICMAC is to analyse driving and dependence power of each practice [51]. A diagram was constructed by plotting dependence power on $X$-axis and driving power on $Y$-axis as shown in Figure 3 and, from the perspectives of driving power and dependence power, this figure demonstrates the distribution of practices. The practices impacting $\mathrm{OP}$ have been classified into four clusters followed by their interpretations:

(1) In the first cluster, there are autonomous practices with weak driving and dependence powers. Such factors are detached because there are few weak links among them. In this case, autonomous cluster is empty, implying that all identified practices are highly interrelated and management should pay serious attention to all those practices of OP.

(2) The second cluster is about dependent factors that have weak driving but strong dependence power, signifying that their improvement mainly depends on the other factors. Innovation and R\&D practices are in this cluster and construct the top level in ISM hierarchy.

(3) Linkage factors constitute the third cluster in which both driving and dependence powers are strong as their values are above the middle of both scales. Such factors are unstable because any action on these variables will have effect on others and also a feedback effect on themselves. That is why they can drive the system but are dependent on other factors as well. TQM, six sigma, ERP, and SCM practices are included in linkage cluster.

(4) Independent factors constitute the last cluster with strong driving power but weak dependence, indicating that their improvement would have ripple effect. In this cluster, we have four practices: LM, QMS, OC, and HRM. They would drive others to achieve the desired objectives and play a key role in the evaluation of operational performance of manufacturing organizations. 


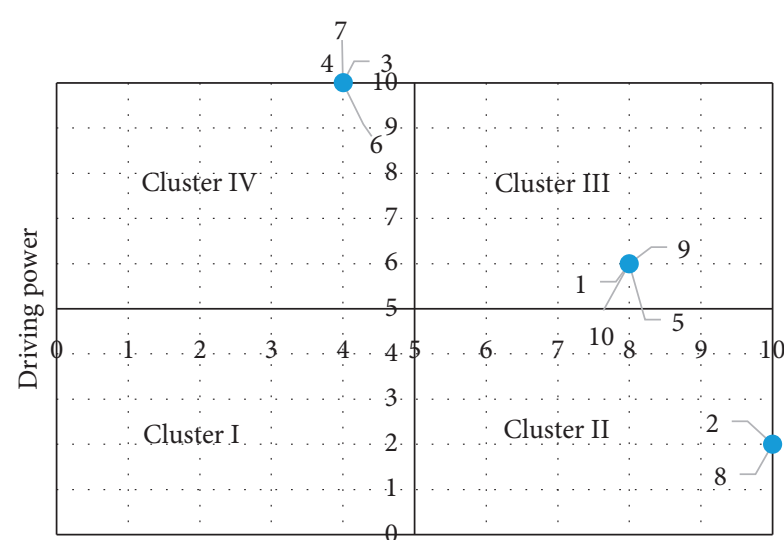

Dependence power

FIGURE 3: Driver power-dependence diagram.

\section{Discussion}

The results of the analysis have been summarized in Figures 2 and 3 presented in the previous section. Figure 2 represents the interactive relationships between the representative key practices influencing OP, whereas Figure 3 reflects the distribution of these practices from the perspective of driving power and dependence power. It can be observed from Figure 2 that "driving practices" are at the bottom level in the hierarchy structure, including P3 (LM), P4 (OC), P6 (HRM), and P7 (QMS). This suggests that actions and priority measures should be taken for these practices. The findings are corroborating the previous studies that have also stated that lean management practices, to a large extent, determine the OP of manufacturing organizations [22, 52-54]. Furthermore, OC is another important driving variable. This established result is also consistent with previous studies. For example, Gambi, Boer [23] concluded that there is a significant relationship between OC and OP. The practices P6 (HRM) and P7 (QMS) are also the driving factors to the OP improvement in the manufacturing organizations. Ahmad and Schroeder [4] and Bayo-Moriones and de Cerio [31] found that HRM dimensions have a significant and positive relationship with OP. Past empirical studies of Feng, Terziovski [33] and Psomas and Kafetzopoulos [34] showed that QMS or ISO 9001 is positively related to OP, which is also consistent with our research findings.

$P 1$ (TQM), P5 (six sigma), P9 (ERP system), and $P 10$ (SCM) are classified as linkage practices in Figure 3. In the hierarchical structure of Figure 2, they are positioned at the intermediate level. They receive the influence from the driving practices and, in turn, exert effects on dependent practices. $P 1, P 5, P 9$, and $P 10$ will be affected by driving practices $(P 3, P 4, P 6$, and $P 7)$. The literature also suggests that $P 3$ (LM), P4 (OC), P6 (HRM), and P7 (QMS) influence $P 1$ (TQM) [55-58]. Furthermore, P3 (LM), P4 (OC), P6 (HRM), and P7 (QMS) also influence P10 (SCM) [59-62]. In turn, $P 1, P 5, P 9$, and $P 10$ will exert influence on the dependent practices such as $P 2$ (INV) and $P 8$ (R\&D). According to Zehir, Ertosun [63] and Chong, Chan [43],
TQM and SCM are sensitive and play a critical role in $P 2$ (process innovation). The two dependent practices $P 2$ (INV) and $P 8(\mathrm{R} \& \mathrm{D})$ in Figure 3 are dependent practices. Their performance would be affected by driving and linkage practices. Performance of these dependent practices depends on how well driving and linkage practices can be steered. For example, performance of dependent practice P2 (INV) is largely determined by the driving practices of $P 3$ (LM), P4 (OC), and P6 (HRM) [64-66].

\section{Conclusion and Practical Implications}

For achieving excellence and world-class performance, global atmosphere and competition put pressure on manufacturing organizations to pursue their quality, productivity, speed, flexibility, and cost reduction; therefore, improvement in contemporary measures of OP should be the aim of manufacturing organizations. There are a number of practices influencing the performance of organizations and the firms cannot put their effort equally on all those practices; even large-scale and profitable organizations may face some kind of resource constraint that may stop them from implementing all those practices simultaneously. By using data collected from academicians and practitioners, this study examined the extent to which enablers or representative practices are adopted by manufacturing organizations and their impact on multiple operational performance dimensions. In order to realize competitiveness, managers should learn about practices that significantly enhance operational performance so that management may effectively incorporate them in their decision-making at strategic and operational levels. Ten fundamental practices were identified based upon extensive literature review and inputs from experts. Then, empirical application of ISM process and MICMAC technique was employed to establish contextual relationships and perform classification of these practices based on their driving and dependence powers. The analysis shows that LM, QMS, OC, and HRM have emerged as drivers making significant contribution to $\mathrm{OP}$, whereas innovation and $\mathrm{R} \& \mathrm{D}$ practices are turned out to be dependent. Further findings indicate that organizations should focus on application of TQM, six sigma, ERP, and SCM as they would help improve innovation and R\&D capabilities of an organization.

The recent work fills the literature gap regarding the comparative effect of enablers on OP of manufacturing organizations as elaborated in Literature Review section. The findings of the current study also carry important implications for the managers/owners of manufacturing companies interested in improving operational performance of their organizations. This model depicts how different practices affecting the OP are interrelated and affect each other, and academicians and senior company managers must be aware of the relative importance of these practices. This suggests that some practices may be strongly related to OP. Finally, considering the limited budget of organizations, managers who strive for perfection and competitiveness should focus more on drivers. The above-stated findings will be helpful in framing competitive strategies for 
manufacturing organizations and providing valuable insights into the strategic role of different practices as an enabler of multiple dimensions of OP. Moreover, this factor profile provides essential information to the decisionmakers for identifying the focal areas and taking due actions to improve OP in manufacturing organizations. Understanding of these representative and interactive practices would help top-level authorities and guide practitioners to make effective regulations, standards, and policies regarding OP enhancement. The critical implications of this study for managers in manufacturing companies are that they should place extra emphasis on LM, HRM, OC, and ISO 9001 implementation, which are of crucial importance for improving and boosting OP. Having a clear understanding of the expected contribution of each kind of practices to OP will assist manufacturing companies in selecting the right processes and strategies that are focused, practical, and effective in prioritizing their expenditures. On the other hand, managers missing the crucial role of drivers may not be able to optimize OP and catch up with competitors. Hence, our study has important implications for the theoretical and practical debate in the area of OP enhancement. Future studies may be conducted to statistically validate the proposed model by using structural equation modelling (SEM) technique. It is the competency of ISM to develop a primary model, whereas SEM provides path coefficients for the different relationships among the practices.

\section{Data Availability}

The data used to support the findings of this study are available from the corresponding author upon request.

\section{Conflicts of Interest}

The authors declare that there are no conflicts of interest regarding the publication of this paper.

\section{References}

[1] R. Ojha, A. K. Vij, and P. Vrat, "Manufacturing excellence and its critical factors," Journal of Advances in Management Research, vol. 11, no. 3, pp. 312-332, 2014.

[2] B. Okwang'a, A. Mungania, and J. Karanja, "Analysis of factors affecting the operational efficiency of Jua kali sector: a case of apparel industry in Nairobi, Kenya," European Journal of Business and Management, vol. 7, no. 30, 2015.

[3] H. Q. Truong, M. Sameiro, A. C. Fernandes et al., "Supply chain management practices and firms' operational performance," International Journal of Quality \& Reliability Management, vol. 34, no. 2, pp. 176-193, 2017.

[4] S. Ahmad and R. G. Schroeder, "The impact of human resource management practices on operational performance: recognizing country and industry differences," Journal of Operations Management, vol. 21, no. 1, pp. 19-43, 2003.

[5] A. B. Abdallah and I. H. Nabass, "Supply chain antecedents of agile manufacturing in a developing country context," Journal of Manufacturing Technology Management, vol. 29, no. 6, pp. 1042-1064, 2018.

[6] S. Modgil and S. Sharma, "Total productive maintenance, total quality management and operational performance," Journal of Quality in Maintenance Engineering, vol. 22, no. 4, pp. 353-377, 2016.

[7] G. A. Marodin, "Lean production and operational performance in the Brazilian automotive supply chain," Total Quality Management \& Business Excellence, vol. 30, no. 3-4, pp. 370-385, 2019.

[8] R. K. Singh, S. K. Garg, and S. G. Deshmukh, "Interpretive structural modelling of factors for improving competitiveness of SMEs," International Journal of Productivity and Quality Management, vol. 2, no. 4, pp. 423-440, 2007.

[9] R. Attri, N. Dev, and V. Sharma, "Interpretive structural modelling (ISM) approach: an overview," Research Journal of Management Sciences, vol. 2319, p. 1171, 2013.

[10] R. Attri, S. Grover, N. Dev, and D. Kumar, "An ISM approach for modelling the enablers in the implementation of Total Productive Maintenance (TPM)," International Journal of System Assurance Engineering and Management, vol. 4, no. 4, pp. 313-326, 2013.

[11] G. Muruganantham, "Application of interpretive structural modelling for analysing barriers to total quality management practices implementation in the automotive sector," Total Quality Management \& Business Excellence, vol. 29, no. 5-6, pp. 524-545, 2018.

[12] K. Baird, K. Jia Hu, and R. Reeve, “The relationships between organizational culture, total quality management practices and operational performance," International Journal of Operations \& Production Management, vol. 31, no. 7, pp. 789-814, 2011.

[13] H. Truong, "The role of quality management practices in operational performance: an empirical study in a transitional economy," in Proceedings of the 1st International Conference on Quality Engineering and Management (ICQEM 2014), Guimaraes, Portugal, September 2014.

[14] H. Kaynak, "The relationship between total quality management practices and their effects on firm performance," Journal of Operations Management, vol. 21, no. 4, pp. 405-435, 2003.

[15] M. Atalay, N. Anafarta, and F. Sarvan, "The relationship between innovation and firm performance: an empirical evidence from Turkish automotive supplier industry," Procedia-Social and Behavioral Sciences, vol. 75, pp. 226-235, 2013.

[16] A. F. Al-Sa'di, A. B. Abdallah, and S. E. Dahiyat, "The mediating role of product and process innovations on the relationship between knowledge management and operational performance in manufacturing companies in Jordan," Business Process Management Journal, vol. 23, no. 2, pp. 349-376, 2017.

[17] R. Y. Y. Hung, B. Y.-H. Lien, B. Yang, C.-M. Wu, and Y.-M. Kuo, "Impact of TQM and organizational learning on innovation performance in the high-tech industry," International Business Review, vol. 20, no. 2, pp. 213-225, 2011.

[18] M. Saunila, "Innovation capability for SME success: perspectives of financial and operational performance," Journal of Advances in Management Research, vol. 11, no. 2, pp. 163-175, 2014.

[19] R. Shah and P. T. Ward, "Lean manufacturing: context, practice bundles, and performance," Journal of Operations Management, vol. 21, no. 2, pp. 129-149, 2003.

[20] G. Nawanir, L. Kong Teong, and S. Norezam Othman, "Impact of lean practices on operations performance and business performance," Journal of Manufacturing Technology Management, vol. 24, no. 7, pp. 1019-1050, 2013.

[21] R. Chavez, C. Gimenez, B. Fynes, F. Wiengarten, and W. Yu, "Internal lean practices and operational performance," 
International Journal of Operations \& Production Management, vol. 33, no. 5, pp. 562-588, 2013.

[22] A. Panwar, R. Jain, A. P. S. Rathore, B. Nepal, and A. C. Lyons, "The impact of lean practices on operational performance-an empirical investigation of Indian process industries," Production Planning \& Control, vol. 29, no. 2, pp. 158-169, 2018.

[23] L. D. N. Gambi, H. Boer, M. C. Gerolamo, F. Jørgensen, and L. C. R. Carpinetti, "The relationship between organizational culture and quality techniques, and its impact on operational performance," International Journal of Operations \& Production Management, vol. 35, no. 10, pp. 1460-1484, 2015.

[24] X. Zu, T. L. Robbins, and L. D. Fredendall, "Mapping the critical links between organizational culture and TQM/Six Sigma practices," International Journal of Production Economics, vol. 123, no. 1, pp. 86-106, 2010.

[25] M. Bozorgi-Nezhad, S. J. Mosavi, and S. Salehi-Kordabadi, Organizational Culture and Quality Management (ISO/9001) Case Study, Tehran Universities Employees, Tehran, Iran, 2012.

[26] I. Alhuraish, C. Robledo, and A. Kobi, "A comparative exploration of lean manufacturing and six sigma in terms of their critical success factors," Journal of Cleaner Production, vol. 164, pp. 325-337, 2017.

[27] M. A. Machinini, The Impact of Six Sigma on Operational Efficiency, North-West University, Potchefstroom, South Africa, 2010.

[28] M. Ertürk, M. Tuerdi, and A. Wujiabudula, "The effects of six sigma approach on business performance: a study of white goods (home appliances) sector in Turkey," Procedia-Social and Behavioral Sciences, vol. 229, pp. 444-452, 2016.

[29] M. M. Parast, "The effect of six sigma projects on innovation and firm performance," International Journal of Project Management, vol. 29, no. 1, pp. 45-55, 2011.

[30] M. A. Jalil, M. A. H. Shaikh, and M. J. Alam, "Human resource management practices and operational performance: an empirical study on kushtia sugar mills ltd," Human Resource Management, vol. 5, no. 1, 2014.

[31] A. Bayo-Moriones and J. Merino-Díaz de Cerio, "Human resource management, strategy and operational performance in the Spanish manufacturing industry,"M@n@gement, vol.5, no. 3, pp. 175-199, 2002.

[32] F. Murmura, "An empirical analysis of ISO 9001: 2008 application in Italian services and manufacturing companies," Total Quality Management \& Business Excellence, vol. 29, no. 7-8, pp. 786-797, 2018 .

[33] M. Feng, M. Terziovski, and D. Samson, "Relationship of ISO 9001: 2000 quality system certification with operational and business performance," Journal of Manufacturing Technology Management, vol. 19, no. 1, pp. 22-37, 2007.

[34] E. Psomas and D. Kafetzopoulos, "Performance measures of ISO 9001 certified and non-certified manufacturing companies," Benchmarking: An International Journal, vol. 21, no. 5, pp. 756-774, 2014.

[35] I. C. Ehie and K. Olibe, "The effect of R\&D investment on firm value: an examination of US manufacturing and service industries," International Journal of Production Economics, vol. 128, no. 1, pp. 127-135, 2010.

[36] H. Ayaydin and İ. Karaaslan, "The effect of research and development investment on Firms'financial performance: evidence from manufacturing firms in Turkey," Bilgi Ekonomisi Ve Yönetimi Dergisi, vol. 9, no. 2, pp. 43-59, 2014.

[37] T. J. Klette, "R \&D, scope economies, and plant performance," The RAND Journal of Economics, vol. 27, no. 3, pp. 502-522, 1996.
[38] H. Anuar, F. Zulhumadi, and Z. Udin, "The role of internal R\&D in operational performance as moderated by intellectual property rights: the Malaysian manufacturing perspective," Journal of Innovation \& Business Best Practice, vol. 2012, Article ID 983677, 15 pages, 2012.

[39] J. E. Hunton, B. Lippincott, and J. L. Reck, "Enterprise resource planning systems: comparing firm performance of adopters and nonadopters," International Journal of Accounting Information Systems, vol. 4, no. 3, pp. 165-184, 2003.

[40] S. Shang and P. B. Seddon, "A comprehensive framework for assessing and managing the benefits of enterprise systems: the business manager's perspective," in Second-Wave Enterprise Resource Planning Systems, pp. 74-101, Cambridge University Press, Cambridge, UK, 2003.

[41] A. Madapusi and D. D'Souza, “The influence of ERP system implementation on the operational performance of an organization," International Journal of Information Management, vol. 32, no. 1, pp. 24-34, 2012.

[42] H. R. HassabElnaby, W. Hwang, and M. A. Vonderembse, "The impact of ERP implementation on organizational capabilities and firm performance," Benchmarking: An International Journal, vol. 19, no. 4/5, pp. 618-633, 2012.

[43] A. Y. L. Chong, F. T. S. Chan, K. B. Ooi, and J. J. Sim, "Can Malaysian firms improve organizational/innovation performance via SCM?" Industrial Management \& Data Systems, vol. 111, no. 3, pp. 410-431, 2011.

[44] J. N. Warfield, "Binary matrices in system modeling," IEEE Transactions on Systems, Man, and Cybernetics, vol. SMC-3, no. 5, pp. 441-449, 1973.

[45] M. Alawamleh and K. Popplewell, "Analysing virtual organisation risk sources: an analytical network process approach," International Journal of Networking and Virtual Organisations, vol. 10, no. 1, pp. 18-39, 2012.

[46] A. P. Pandi, P. R. Sethupathi, and D. Jeyathilagar, "IEQMS model: a leveraging mechanism to polarise quality in engineering educational institutions-an empirical study," International Journal of Manufacturing Technology and Management, vol. 28, no. 4-6, pp. 257-274, 2014.

[47] A. Garg, B. Shukla, and G. Kendall, "Barriers to implementation of IT in educational institutions," International Journal of Information and Learning Technology, vol. 32, no. 2, pp. 94-108, 2015.

[48] P. Kumar, F. Ahmed, R. K. Singh, and P. Sinha, "Determination of hierarchical relationships among sustainable development goals using interpretive structural modeling," Environment, Development and Sustainability, vol. 20, no. 5, pp. 2119-2137, 2018.

[49] M. D. Singh and R. Kant, "Knowledge management barriers: an interpretive structural modeling approach," International Journal of Management Science and Engineering Management, vol. 3, no. 2, pp. 141-150, 2008.

[50] J.-C. Duperrin and M. Godet, Méthode de hiérarchisation des éléments d'un système: essai de prospective du système de l'énergie nucléaire dans son contexte sociétal, C.E.N. Saclay, Saclay, France, 1973.

[51] A. Mandal and S. G. Deshmukh, "Vendor selection using interpretive structural modelling (ISM)," International Journal of Operations \& Production Management, vol. 14, no. 6, pp. 52-59, 1994.

[52] S. Rahman, T. Laosirihongthong, and A. S. Sohal, "Impact of lean strategy on operational performance: a study of Thai manufacturing companies," Journal of Manufacturing Technology Management, vol. 21, no. 7, pp. 839-852, 2010. 
[53] G. Dal Pont, A. Furlan, and A. Vinelli, "Interrelationships among lean bundles and their effects on operational performance," Operations Management Research, vol. 1, no. 2, pp. 150-158, 2008.

[54] V. Yadav, R. Jain, M. L. Mittal, A. Panwar, and A. Lyons, “The impact of lean practices on the operational performance of SMEs in India," Industrial Management \& Data Systems, vol. 119, no. 2, pp. 317-330, 2019.

[55] R. Dubey, T. Singh, S. S. Ali, and S. Tiwari, "Contextual relationship among antecedents of truck freight using interpretive structural modelling and its validation using MICMAC analysis," International Journal of Logistics Systems and Management, vol. 20, no. 1, pp. 42-62, 2015.

[56] J. A. Gimenez-Espin, D. Jiménez-Jiménez, and M. MartinezCosta, "Organizational culture for total quality management," Total Quality Management \& Business Excellence, vol. 24, no. 5-6, pp. 678-692, 2013.

[57] A. Shahraki, M. J. Paghaleh, and M. Zarei, "HRM effects on TQM," Business Management Dynamics, vol. 1, no. 3, p. 1, 2011.

[58] W. Lewis, K. Pun, and T. Lalla, "The effect of ISO 9001 on TQM implementation in SME in trinidad," West Indian Journal of Engineering, vol. 30, no. 1, pp. 1-16, 2007.

[59] C. D. Singh, "Application of lean and JIT principles in supply chain management," International Journal of Management Research and Business Strategy, vol. 2, no. 1, pp. 85-98, 2013.

[60] J. E. Mello and T. P. Stank, "Linking firm culture and orientation to supply chain success," International Journal of Physical Distribution \& Logistics Management, vol. 35, no. 8, pp. 542-554, 2005.

[61] M. Gómez-Cedeño, J. M. Castán-Farrero, L. Guitart-Tarrés, and J. Matute-Vallejo, "Impact of human resources on supply chain management and performance," Industrial Management \& Data Systems, vol. 115, no. 1, pp. 129-157, 2015.

[62] D. Prajogo, B. Huo, and Z. Han, "The effects of different aspects of ISO 9000 implementation on key supply chain management practices and operational performance," Supply Chain Management: An International Journal, vol. 17, no. 3, pp. 306-322, 2012.

[63] C. Zehir, Ö. G. Ertosun, S. Zehir, and B. Müceldilli, "Total quality management practices' effects on quality performance and innovative performance," Procedia-Social and Behavioral Sciences, vol. 41, pp. 273-280, 2012.

[64] A. K. Möldner, J. A. Garza-Reyes, and V. Kumar, "Exploring lean manufacturing practices' influence on process innovation performance," Journal of Business Research, vol. 106, pp. 233-249, 2020.

[65] J. C. Naranjo-Valencia, D. Jiménez-Jiménez, and R. SanzValle, "Studying the links between organizational culture, innovation, and performance in Spanish companies," Revista Latinoamericana de Psicología, vol. 48, no. 1, pp. 30-41, 2016.

[66] M. Diaz-Fernandez, M. Bornay-Barrachina, and A. LopezCabrales, "HRM practices and innovation performance: a panel-data approach," International Journal of Manpower, vol. 38, no. 3, pp. 354-372, 2017. 